\title{
Practical methods for water discharge measurements in fluvial sections
}

\author{
D. Mirauda, M. Greco \& P. Moscarelli \\ Department of Environmental Engineering and Physics, \\ Basilicata University, Italy
}

\begin{abstract}
Recent aims and developments in water resource policies and management have been to achieve a high level of protection in both river systems as well as in the environment by natural hazard prevention and/or reduction. In river water management, the lack of direct field measures resulting from the necessity to dedicate long periods of time and effort represents a weakness in control and forecasting procedures. This paper is in reference to a detailed series of monitoring activities performed on Alzette river, in Grand-Duchy of Luxembourg and on Lucanian rivers in Southern Italy by applying the expeditive methodology for water discharge measurement and assessment, which allows maintaining high quality data and results.
\end{abstract}

Keywords: river flow, velocity, measure, error, river monitoring.

\section{Introduction}

The river flow forecasting represents a crucial point to employ for improving a management policy addressed to the right use of water resources as well as for conjugating prevention and defense actions against environmental degradation. Indeed, the European directive 2000/60/CEE [2] states the relevance of the monitoring and control activities as support to define the whole of protection measures to adopt for achieving the "good state" of the water body. Thus, the quantitative monitoring of rivers is an essential step for environmental purposes both for addressing middle and long term surveillance and control activities, and for civil protection aims in terms of flood forecasting and risk mitigation. A correct quantitative knowledge of the fluvial flow cannot apart from experimental observations and measures. The development of numerical 
simulation models and forecasting models does not have, in fact, eliminated the needed to collect hydrological data which are fundamental for their calibration $[5,7]$. Therefore it is evident the necessity to have a monitoring network able to continuously acquire the flow depth and velocity in river control sections. Integrating these two items, the water discharge can be strictly evaluated. Generally, the measure of level in a fluvial section is obtained in simple way, with not excessively elevated costs, by the use of acoustic or pressure sensors [4]. The measure of depth is then converted in values of discharge on the base of flow depth/discharge ratio in each gauged section in which the accuracy depends on the availability of velocity measures during flood events particularly.

Nevertheless, the velocity measure with standard techniques, based on the use of current meter and acoustic sensors, requires high costs and presents notable difficulties during flood events, properly, for both limited sampling of the velocity in the lower part of the cross section and operator safety related to the elevated traction of the carrying cables. Such difficulties can be overcome using non contact sensors whose, however, present some problems due to their calibration [1].

Thus, the difficulties occurring during the field activities encourage the development and implementation of operative computation methods and/or measuring technologies addressed to time reduction for data acquisition and processing maintaining a good level of accuracy. Such methods, already discussed by same authors [3], has been tested in ungauged sections located along the Alzette river, in Grand-Duchy of Luxembourg and in gauged sections along main rivers of Basilicata region (Southern Italy).

\section{Ungauged and gauged sections}

The results presented and discussed below are referred to field measurements collected on three ungauged sections located along the Alzette river in GrandDuchy of Luxembourg and on three gauged sections located on two main rivers of Basilicata region (Southern-Italy).

The Alzette river is born in France to around 4 kilometers from the frontier of Luxembourg and is the main tributary of the Sûre, flowing into the Moselle river, which is tributary of the Rhine river. It is characterized by a seasonal variation of the flows: elevated levels in winter and low summer levels, with minima levels during the month of September. The three measure sections are located in the northern part of the river in the valley where the slope presents values of about $1 \%$ (fig. 1).

The first section, named Hunsdorf, is located on a meandered branch of the river with gravel bed and banks constituted by piers (fig. 2a).

The second section, named Lintgen, presents a fine sand and silt bed and the banks are similar to the previous section (fig. 2 b).

The third section, named Mersch, is along a regularized reach with banks and bed covered by reinforced concrete (fig. 2c). 


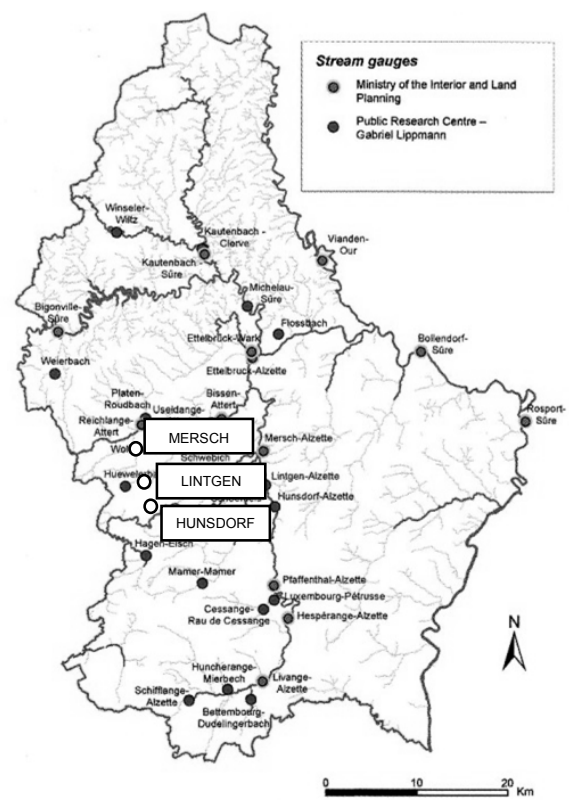

Figure 1: $\quad$ Alzette river with location of river ungauged sections.

a)

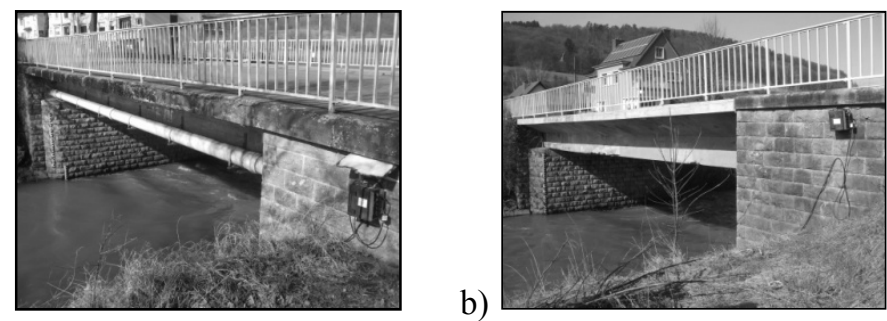

c)

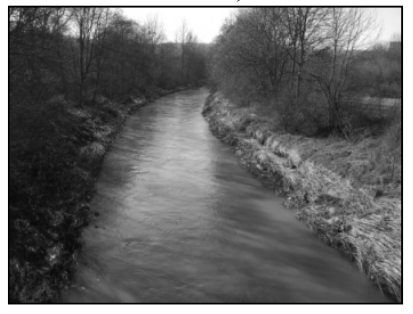

Figure 2: Ungauged sections: a) Hunsdorf, b) Lintgen and c) Mersch. 

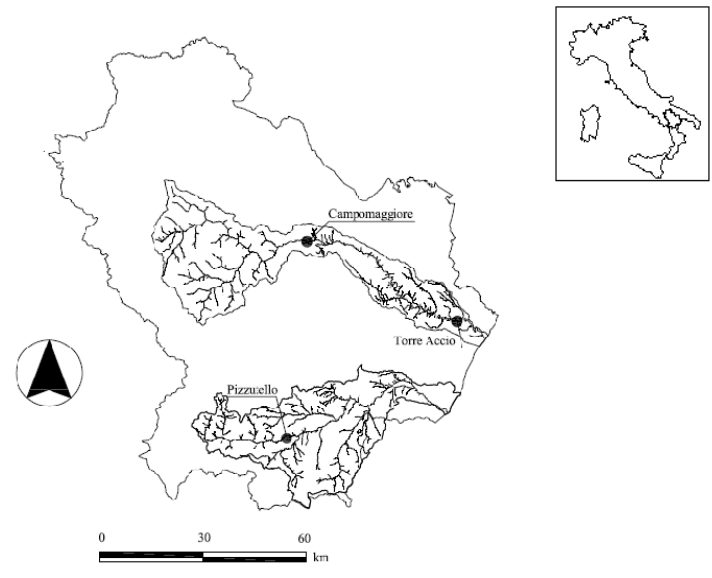

Figure 3: Investigated gauge stations along Basento and Sinni rivers.

Instead, the three sections of Basilicata region are hydrometric stations. Fig. 3 reports the basins of Basento and Sinni rivers with the location of the three sections.

The first gauged station, named Campomaggiore, is located in the upper part of the Basento river, where the slope is relatively high, about $1 \%-2 \%$, and the river bed narrows and engraves more deeply the sides (fig. 4a). The banks are very steep and covered by shrubby vegetation mainly. No-submerged rigid vegetation is even present. The main channel is characterized by the presence of boulders and cobbles carried down during relevant flood events.

The second equipped site, named Torre Accio, is located in the valley part of the river, where the slope reduces at about $0.1 \%$ (fig. $4 \mathrm{~b}$ ). Here, the reach is characterized by the presence of fine sand and silt sediments and the bank slope and cross section remain sufficiently stable during ordinary flood events. In this reach, the Basento river can be considered meandering and sometimes the presence of aquatic vegetation influences the flow, mainly in the case of low stages. The banks are covered by shrubby and cane vegetation.

The third section, named Pizzutello, is located in the middle-upper part of the Sinni river, where the slope is about $0.1-0.2 \%$ (fig. $4 \mathrm{c}$ ). The river stretch, including this section, presents plan pattern tending to a single reach. The banks are characterized by thick vegetation that slow down flow velocity during flood events generally.

For the sections of Hunsdorf, Lintgen, Campomaggiore, Torre Accio and Pizzutello the velocity measurements were performed by using a current meter stabilized by a heavy lead weight lowered from the bridges with a mobile trolley system while for the section of Mersch the velocity measurements have been acquired by Workhorse Rio Grande ADCP.

Table 1 shows the observed ranges of the mean depths and the water discharges in the investigated sites. 
a)
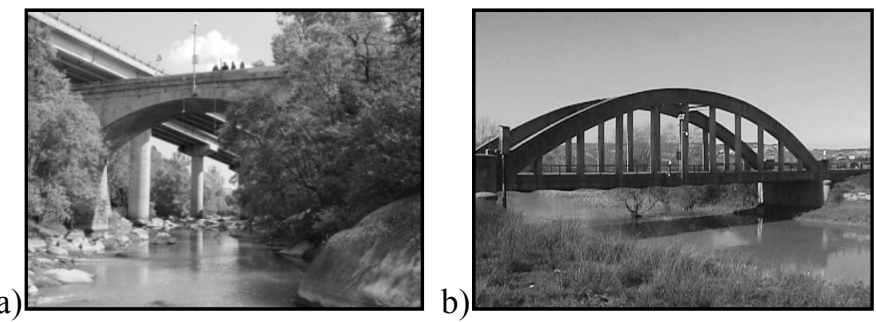

c)

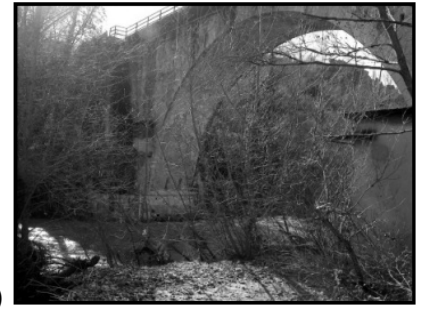

Figure 4: Gauged stations: a) Campomaggiore, b) Torre Accio and c) Pizzutello.

Table 1: Ranges of the mean depths and the water discharges in the investigated sites.

\begin{tabular}{c|c|c}
\hline Nome of section & Mean depth $(\mathrm{m})$ & Water discharge $\left(\mathrm{m}^{3} / \mathrm{s}\right)$ \\
\hline Hunsdorf & $0,22-2,90$ & $3,1-44,2$ \\
\hline Lintgen & $0,31-2,80$ & $3,9-49,2$ \\
\hline Mersch & $0,17-2,71$ & $2,3-44,3$ \\
\hline Campomaggiore & $0,30-3,42$ & $0,9-62,3$ \\
\hline Torre Accio & $0,27-5,65$ & $0,8-180,3$ \\
\hline Pizzutello & $0,11-1,54$ & $0,4-24,2$ \\
\hline
\end{tabular}

\section{Methods for the evaluation of the water discharge}

The evaluation of river water discharge has been performed according to the rule ISO 748/1997 [6], using the velocity-area method which represents an efficient and reliable tool. Operatively, computations require one to divide the section areas into several verticals and a further subdivision of each vertical into discrete points, in order to evaluate the mean velocity of the flow along each vertical.

The number of verticals and the distribution inside the cross section has been chosen case by case based on section width, riverbed geometry and flow regimes and characteristics, while the measurement points are fixed according to the measurement methodology used, that is, by wading or bridge, and to technique.

The main objective was to obtain a correct evaluation of the mean velocity for each vertical and measurement section which is related to a reliable reconstruction of flow field obtained through velocity point measurements in several marks of hydraulic sections generally distributed from bottom up to the 
free surface flow. Depending on the velocity measure points, the mean velocity has been calculated. Once evaluated the mean velocity for each vertical, the water discharge was calculated by the way of the mean-section method or mid section method [6]. In the first one, the partial discharge is computed by multiplying the average value of mean velocities of two adjacent verticals times the area included in the respective verticals. The equation of the partial discharge between two verticals 1 and 2 , with depth $d_{1}$ and $d_{2}$, mean velocities $v_{1}$ and $v_{2}$ and the horizontal distance between the two verticals $b$, is the following:

$$
\mathrm{q}=\left(\frac{\overline{\mathrm{v}}_{1}+\overline{\mathrm{v}}_{2}}{2}\right) \cdot\left(\frac{\mathrm{d}_{1}+\mathrm{d}_{2}}{2}\right) \cdot \mathrm{b}
$$

This is repeated for each segment and the total discharge is obtained by adding the partial discharge from each segment.

In the second method the partial discharge between two verticals is obtained as the product of each value of the mean velocity times the depth $d_{i}$ and the sum of the semi-distance between the adjacent verticals. The total discharge is obtained by summing these partial discharges in the following way:

$$
Q=\sum \bar{v}_{i} d_{i} \frac{b_{i}+b_{i+1}}{2}
$$

In order to reduce the time of data acquisition and processing a quick methodology has been proposed which has allowed to compute the discharge with equations 1 and 2 considering the points velocities along only three main verticals (i.e., placed at $1 / 4,1 / 2$ and $3 / 4$ or $1 / 3,1 / 2$ and $2 / 3$ of the total observed width) and considering the points velocities in $30 \%$ or $50 \%$ of the area below the free surface. In particular the first method considers only three verticals placed at $1 / 4,1 / 2$ and $3 / 4$ and using all points velocities along these verticals (method named as 3 vert). The choice of these verticals refers to the expedite procedure commonly used for suspended sediment sampling and allows to carry on a possible correlation when both measurements, velocity and sediment transport, are performed. The second method considers the same verticals but uses only the point velocities in $30 \%$ of the area below the free surface (method named as $30 \%$ depth). The third method considers the point velocities in $50 \%$ of the area below the free surface (method named as 50\% depth). The choice of $30 \%$ and $50 \%$ of the area deals with the rationale that in a river flow the large amount of the moving fluid volume (discharge) is generally concentrated in such area where the maximum velocity usually occurs. The fourth method takes into account, as alternative, other verticals placed at $1 / 3,1 / 2$ and $2 / 3$ of the flow width instead of the previous and using all points velocities along the verticals. Such alternative has been proposed supposing that the main body of the flow is usually confined in the middle part of the current and, further, to reduce the boundary influence in the velocity field measurements.

The other two methods consider the same verticals using the points velocities at $30 \%$ and $50 \%$ of the area below the free surface. 


\section{Discussion of the results}

The accuracy of the different methods above described has been evaluated through the calculation of the percentage error defined as follows:

$$
\varepsilon \%=\left(\frac{Q_{m_{i}}-Q_{c_{i}}}{Q_{m_{i}}}\right) 100
$$

in which $Q_{m_{i}}$ represent the water discharge computed with all velocity points while $Q_{c_{i}}$ the water discharge computed with the quick methods described above. The error presents a negative value when the first discharge is great of the second discharge. The distribution of errors for the six methods and the discharge calculated with the mid-section method for Alzette river is plotted in figs. 5a and $5 \mathrm{~b}$.

a)

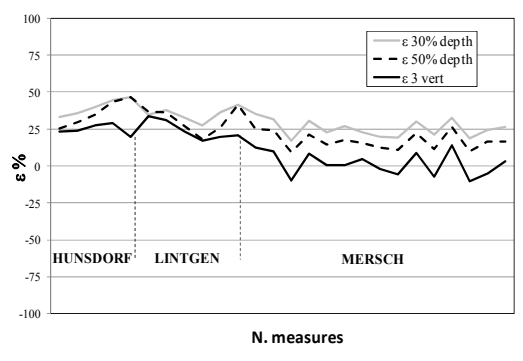

b)

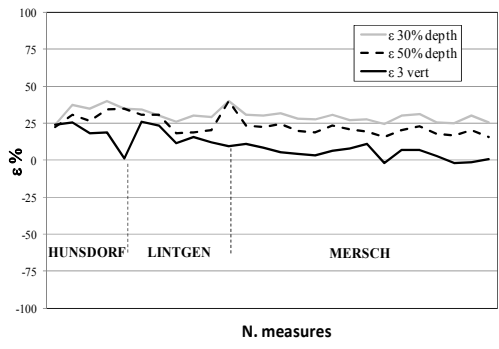

Figure 5: Error distribution for the mid-section method in the Alzette sections a) verticals placed at $1 / 3,1 / 2$ and $2 / 3 ;$ b) verticals placed at $1 / 4,1 / 2$ and $3 / 4$.

Considering as maximum acceptable error during quick field measurements the value of $30 \%$, from the fig. 5 it is possible to observe that the methods of three verticals placed respectively at $1 / 3,1 / 2$ and $2 / 3$ and at $1 / 4,1 / 2$ and $3 / 4$ provide all the measures for the Hunsdorf and Mersch sections with an error less than the maximum one. For the Lintgen section, instead, in the method of three verticals placed at $1 / 3,1 / 2$ and $2 / 3$ (fig. 5 b) the error increases. Moreover fig. 5 shows as the error increases considering the points velocities in $30 \%$ or $50 \%$ of the area below the free surface. In order to better understand such behaviour, Table 2 reports the percentage of the measures which present an absolute percentage error less than $30 \%$ for all methods.

The calculations of the discharge with the mean-section method show an error greater than those observed for the mid-section method (fig. 6 and table 3), leading as the mid-section methods offers some advantages over the meansection method even for computational time reduction [7]. 
Table 2: $\quad$ Percentage of the measures with an absolute error less than $30 \%$ using the mid-section method for Alzette sections.

\begin{tabular}{c|c|c|c|c|c|c|}
\cline { 2 - 7 } & \multicolumn{2}{|c|}{$1 / 3-1 / 2-2 / 3$ Method } & \multicolumn{2}{c|}{$1 / 4-1 / 2-3 / 4$ Method } \\
\cline { 2 - 7 } & $\begin{array}{c}3 \\
\text { verticals }\end{array}$ & $\begin{array}{c}50 \% \\
\text { depth }\end{array}$ & $\begin{array}{c}30 \% \\
\text { depth }\end{array}$ & $\begin{array}{c}3 \\
\text { verticals }\end{array}$ & $\begin{array}{c}50 \% \\
\text { depth }\end{array}$ & $\begin{array}{c}30 \% \\
\text { depth }\end{array}$ \\
\hline Hunsdorf & $100 \%$ & $40 \%$ & $0 \%$ & $100 \%$ & $40 \%$ & $20 \%$ \\
\hline Lintgen & $67 \%$ & $50 \%$ & $17 \%$ & $100 \%$ & $67 \%$ & $67 \%$ \\
\hline Mersch & $100 \%$ & $100 \%$ & $73 \%$ & $100 \%$ & $100 \%$ & $80 \%$ \\
\hline
\end{tabular}

a)

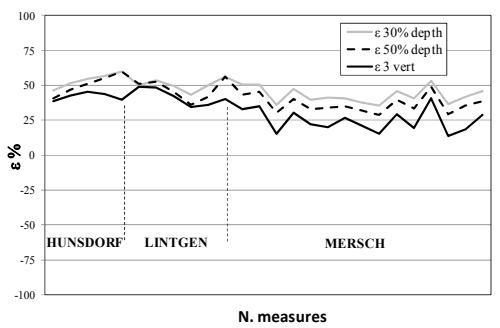

b)

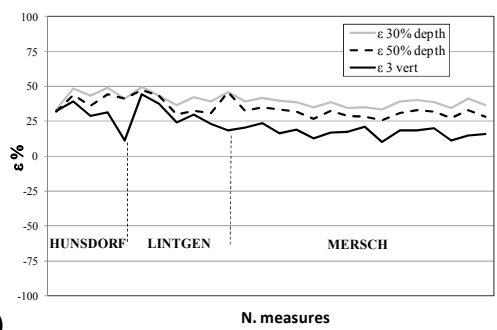

Figure 6: Error distribution for the mean-section method in the Alzette sections a) verticals placed at $1 / 3,1 / 2$ and $2 / 3$; b) verticals placed at $1 / 4,1 / 2$ and $3 / 4$.

Table 3: $\quad$ Percentage of the measures with an absolute percentage error less than $30 \%$ using the mean-section method and considering all three methods for Alzette sections.

\begin{tabular}{c|c|c|c|c|c|c|}
\cline { 2 - 7 } & \multicolumn{2}{|c|}{$1 / 3-1 / 2-2 / 3$ Method } & \multicolumn{2}{c|}{$1 / 4-1 / 2-3 / 4$ Method } \\
\cline { 2 - 7 } & $\begin{array}{c}3 \\
\text { verticals }\end{array}$ & $\begin{array}{c}50 \% \\
\text { depth }\end{array}$ & $\begin{array}{c}30 \% \\
\text { depth }\end{array}$ & $\begin{array}{c}3 \\
\text { verticals }\end{array}$ & $\begin{array}{c}50 \% \\
\text { depth }\end{array}$ & $\begin{array}{c}30 \% \\
\text { depth }\end{array}$ \\
\hline Hunsdorf & $0 \%$ & $0 \%$ & $0 \%$ & $40 \%$ & $0 \%$ & $0 \%$ \\
\hline Lintgen & $0 \%$ & $0 \%$ & $0 \%$ & $67 \%$ & $17 \%$ & $0 \%$ \\
\hline Mersch & $73 \%$ & $20 \%$ & $0 \%$ & $100 \%$ & $40 \%$ & $0 \%$ \\
\hline
\end{tabular}

Generally for all methods the errors of the Mersch sections are less than those of the other sections. The reason for such different behavior could be found in the different equipment and methodology used for the velocity data acquisition in such section which would result more precise.

For the gauged stations of Basilicata region, the behavior seems to be different (fig. 7 and 8). In fact, the error lightly increases respect to the cases of Alzette river. Such increase is especially evident when only the points velocities in $30 \%$ of the area below the free surface are considered. Table 4 reports the percentage of the measures which present an absolute percentage error less that $30 \%$. 
a)

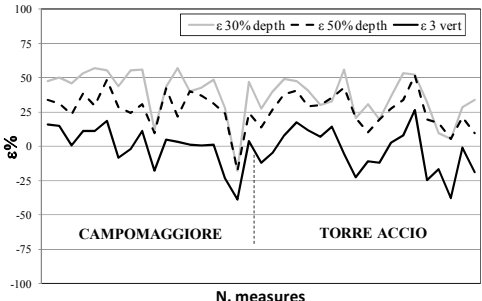

c)

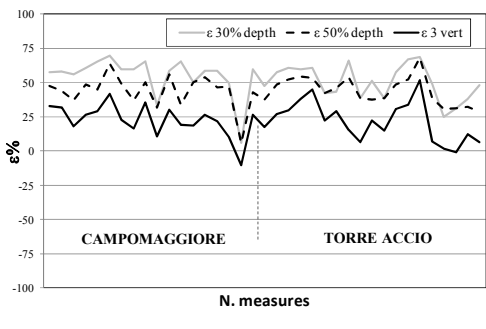

b)

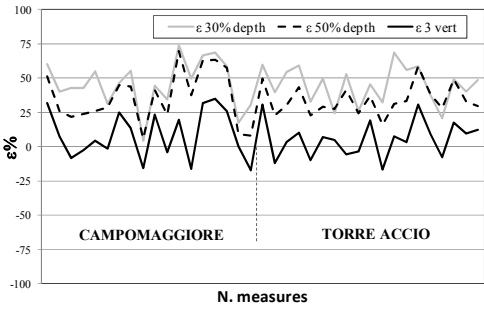

d)

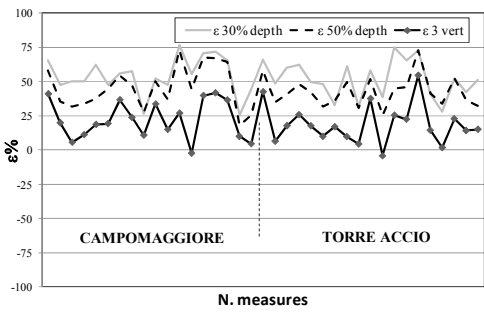

Figure 7: Error distribution for Basento sections: a) discharge calculated with the mid-section method and verticals placed at $1 / 3,1 / 2$ and $2 / 3$; b) discharge calculated with the mid-section method and verticals placed at $1 / 4,1 / 2$ and $3 / 4$; c) discharge calculated with the meansection method and verticals placed at $1 / 3,1 / 2$ and $2 / 3$; d) discharge calculated with the mean-section method and verticals placed at $1 / 4,1 / 2$ and $3 / 4$.

Table 4: $\quad$ Percentage of the measures with an absolute percentage error less than $30 \%$ using the mid-section and mean-section methods and considering all three methods for Lucanian sections.

\begin{tabular}{|c|c|c|c|c|c|}
\hline & & & Campomaggiore & Torre Accio & Pizzutello \\
\hline \multirow{6}{*}{ 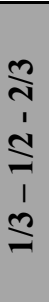 } & \multirow{3}{*}{$\begin{array}{c}\text { Mid } \\
\text { Method }\end{array}$} & 3 verticals & $94 \%$ & $95 \%$ & $88 \%$ \\
\hline & & $50 \%$ depth & $50 \%$ & $68 \%$ & $35 \%$ \\
\hline & & $30 \%$ depth & $17 \%$ & $42 \%$ & $12 \%$ \\
\hline & \multirow{3}{*}{$\begin{array}{c}\text { Mean } \\
\text { Method }\end{array}$} & 3 verticals & $78 \%$ & $74 \%$ & $18 \%$ \\
\hline & & $50 \%$ depth & $6 \%$ & $5 \%$ & $0 \%$ \\
\hline & & $30 \%$ depth & $6 \%$ & $5 \%$ & $0 \%$ \\
\hline \multirow{6}{*}{ 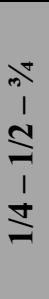 } & \multirow{3}{*}{$\begin{array}{c}\text { Mid } \\
\text { Method }\end{array}$} & 3 verticals & $83 \%$ & $89 \%$ & $100 \%$ \\
\hline & & $50 \%$ depth & $50 \%$ & $42 \%$ & $53 \%$ \\
\hline & & $30 \%$ depth & $11 \%$ & $16 \%$ & $29 \%$ \\
\hline & \multirow{3}{*}{$\begin{array}{c}\text { Mean } \\
\text { Method }\end{array}$} & 3 verticals & $67 \%$ & $84 \%$ & $76 \%$ \\
\hline & & $50 \%$ depth & $17 \%$ & $5 \%$ & $18 \%$ \\
\hline & & $30 \%$ depth & $11 \%$ & $5 \%$ & $0 \%$ \\
\hline
\end{tabular}


a)

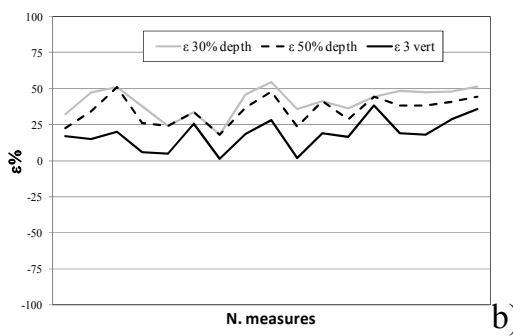

c)

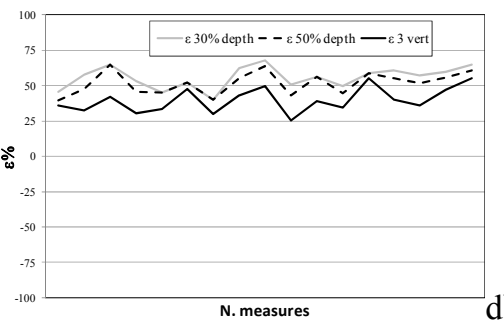

b)

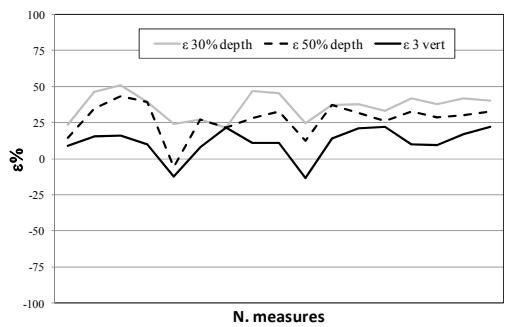

d)

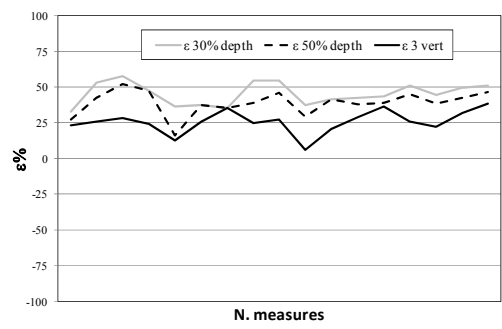

Figure 8: Error distribution for Sinni section: a) discharge calculated with the mid-section method and verticals placed at $1 / 3,1 / 2$ and $2 / 3 ; b$ ) discharge calculated with the mid-section method and verticals placed at $1 / 4,1 / 2$ and $3 / 4$; c) discharge calculated with the meansection method and verticals placed at $1 / 3,1 / 2$ and $2 / 3$; d) discharge calculated with the mean-section method and verticals placed at $1 / 4,1 / 2$ and $3 / 4$.

a)

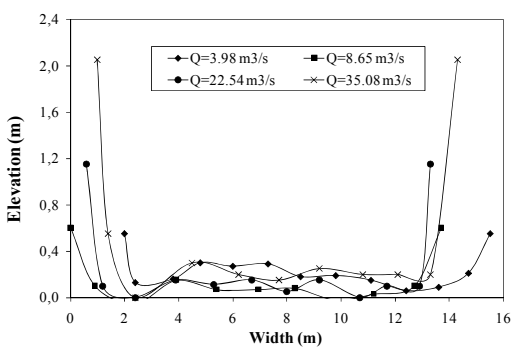

b)

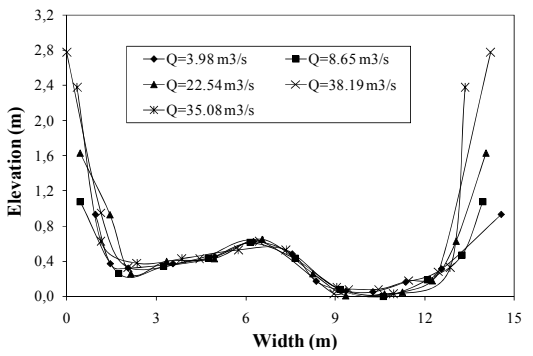

c)

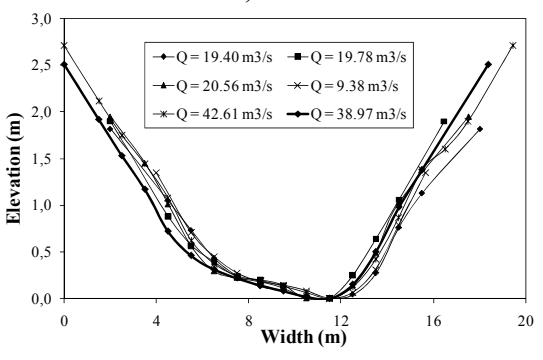

Figure 9: Cross section elevation: a) Hunsdorf; b) Lintgen and c) Mersch outlined for some values of discharge. 
The reason of such growth could be searched in the different configuration of the sections of Alzette river whose are much more regular even for increasing discharge (fig. 9), while the cross sections of Lucanian rivers show a general irregular geometries slightly changing for increasing stages (fig. 10). Figures 9 and 10 report the cross section elevation referred to the local river bottom.

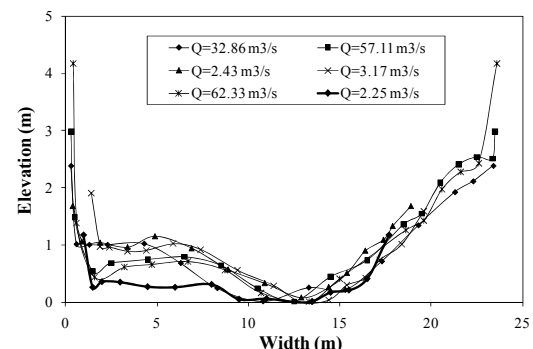

a)

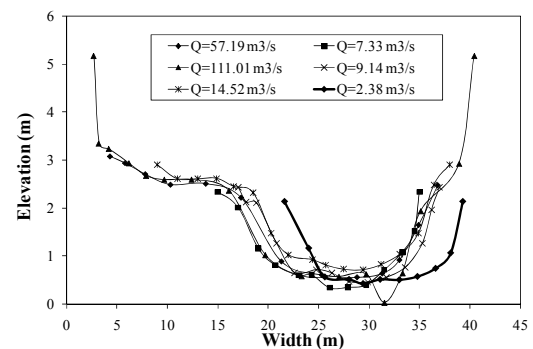

b)

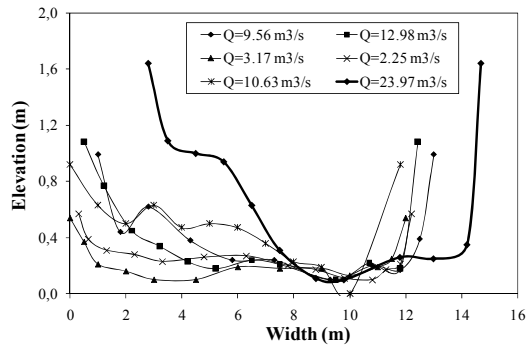

c)

Figure 10: Cross section elevation: a) Campomaggiore; b) Torre Accio and c) Pizzutello outlined for some values of discharge.

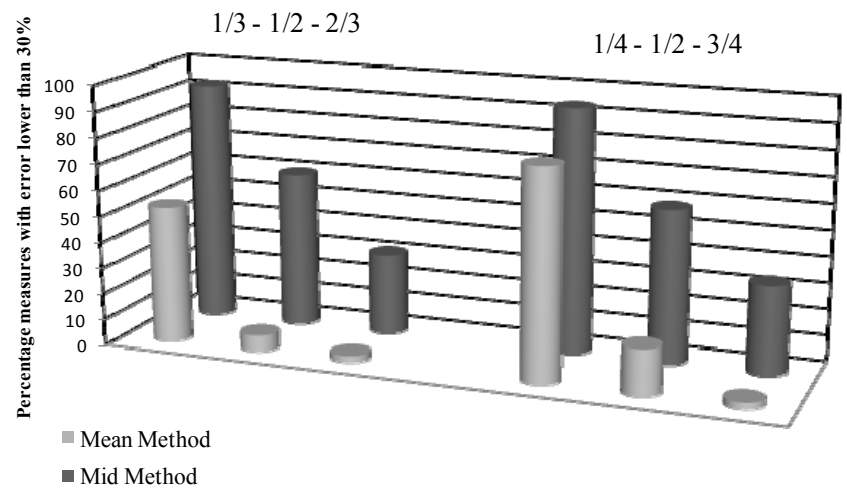

Figure 11: Percentage of the measures with an absolute percentage error less than $30 \%$ for all methods and the whole data set. 
Plotting in one graph the percentage of the measure whose present an absolute percentage error less than $30 \%$ for all methods and considering the whole dataset of measures, it is possible to note that the best methods are those with the discharge computed through the mid-section method and the three verticals with all velocity points along the verticals.

\section{Conclusions}

Water discharge measurements in a river require acquisition techniques, methods and data processing procedures capable to reduce both field operation and computational time maintaining a high quality and reliability levels of the results. In this paper the possibility of fitting field measurements, obtained for several rivers through the use of conventional and modified methods, has been evaluated. The aim deals with the opportunity to propose an expeditive field measurement procedure based on a reduced number of verticals to be employed for flow discharge assessment using classical equipment (current meter and/or acoustic sensors). Three base verticals are employed during the measures in two different configurations $(1 / 3,1 / 2$ and $2 / 3$ of the river width and $1 / 4,1 / 2$ and $3 / 4)$. The results show how the differences between the water discharge data calculated by the use of all measured velocity points and those obtained through the three verticals methods are always ranging into $+/-30 \%$ rising a good acceptance for early field measurements. Besides, it is also possible to note as the error lightly increases as the shape of the cross section tends to be irregular. Finally, the best methods result those with the discharge computed with the midsection method and the three verticals with all velocity points.

\section{Acknowledgements}

The authors thank Dr. Patrick Matgen and Dr. Laurent Pfister of the CRP Gabriel Lippmann of Grand-Duchy of Luxembourg for their precious assistance.

\section{References}

[1] Costa, J.E., Spicer, K.R., Cheng, R.T., Haeni, F.P., Melcher, N.B., Thurman, E.M., Plant, W.J. \& Keller, W.C., 2000, Measuring stream discharge by non-contact methods - a proof of concept experiment. Geophys. Res. Let., 27(4), pp.553-556, 2000.

[2] Directive 2000/60/CE of 23/10/2000. Water Framework Directive. EC OJ n. L 327 of 22/12/2000, 2000.

[3] Greco M. \& Mirauda D., Expeditive methodology for river water discharge evaluation. River Flow 2004, (eds.) Greco, Carravetta \& Della Morte, Taylor \& Francis Group, London, ISBN 905809658 0, 1, pp. 487-493, 2004.

[4] Herschy, R.W., Hydrometry: Principles and Practices, J. Wiley \& Sons, Chichester, U.K., 1999. 
[5] Horritt, M.S. \& Bates, P.D., Evaluation of 1-D and 2-D models for predicting river flood inundation. J. Hydrol., 268, pp.87-99, 2002.

[6] ISO 748, Measurement of liquid flow in open channel - Velocity-area methods, 1997.

[7] Pappenberger, F., Matgen, P., Beven, K. J., Henry, J.B., Pfister, L. \& de Fraipont, P. Influence of uncertain boundary conditions and model structure on flood inundation predictions, Adv. Water Resour. 29, pp. 1430-1449, 2006. 